ISSN: $1980-055 X$

\title{
REGIONALIZAÇÃO SAZONAL E MENSAL DA PRECIPITAÇÃO PLUVIAL MÁXIMA NO ESTADO DO RIO GRANDE DO SUL
}

\author{
Fabiane Pereira Britto ${ }^{1}$, Rodrigo Barletta ${ }^{2}$, Magaly Mendonça ${ }^{3}$
}

\begin{abstract}
RESUMO
Este trabalho tem como objetivo caracterizar a precipitação pluvial e identificar os sistemas atmosféricos que atuam no Estado do Rio Grande do Sul. Foram utilizados dados mensais de precipitação pluvial do período entre 1967 a 1998, de 14 Estações Meteorológicas. O comportamento espaço - temporal da precipitação pluvial, foi analisado através da variabilidade sazonal e mensal. Totais médios de pluviosidade foram calculados para cada estação meteorológica. Posteriormente, efetuou-se uma análise e interpretação de distribuição dos totais de precipitação pluvial (sazonal e mensal) que possibilitaram a análise e interpretação dos dados. Sazonalmente, no litoral e no centro-sul do Estado, os meses de inverno são os mais chuvosos, devido a freqüência de passagens dos sistemas frontais. No sudoeste do Estado, o outono é mais chuvoso, devido a atuação dos bloqueios atmosféricos. No noroeste os meses da primavera são os mais chuvosos, devido a formação dos Complexos Convectivos de Mesoescala. No nordeste o verão é mais chuvoso, em função das chuvas convectivas associadas a sistemas atmosféricos como a Zona de Convergência do Atlântico Sul.
\end{abstract}

Palavras chaves: Precipitação pluvial, variabilidade e sistemas atmosféricos.

\section{SEAZONAL REGIONALIZATION AND MONTHLY RAINFALL HIGH PRECIPITATION AN RIO GRANDE DO SUL STATE}

\begin{abstract}
This work aims to characterize the rainfall and to identify atmospheric systems that act in the Rio Grande do Sul State. Monthly data from the period between 1967 and 1998 were used, sampled at the 14 meteorological stations. The time-spacial rainfall behavior were analised by the seasonal and monthly variability. Total mean values were calculated for each

${ }^{1}$ Geógrafa, Mestre em Geografia, Instituto Ambiental Ratones (IAR), Rua dos Jasmins 167, Santa Mônica, Cep: 88037-145, Florianópolis, Santa Catarina.

2 Oceanólogo, Doutor em Engenharia Ambiental, Laboratório de Hidráulica Marinha (LAHIMAR), Caixa Postal 5039, Universidade Federal de Santa Catarina (UFSC), Campus Trindade, Cep: 88040-970, Florianópolis, Santa Catarina.

3 Geógrafa, Doutora em Geografia, Laboratório de Climatologia, Departamento de Geociências (CFH), Universidade Federal de Santa Catarina (UFSC), Campus Trindade, Caixa Postal 476, Cep: 88040-970, Florianópolis, Santa Catarina.
\end{abstract}


meteorological stations. Further, data analisys and interpretation were realized on the rainfall (seasonal and monthly). Seasonal, data for the costal and central state, show that winter months are more rainny, due to the frequency of the frontal systems passage. At the southwest, auttumn is more rainny, due to atmospherical blocking. At the northwest, spring months are more rainny, due to Mesoscale Convective Complex formation. At the northeast, summer is more rainny, is a function of convective rain associated to atmospheric system like the South Atlantic Convergence Zone.

Key words: rainfall, variability and atmospheric systems.

\section{Introdução}

A variabilidade climática pode afetar de forma importante a vida econômica e social da população em geral, na geração de energia, nas atividades agrícolas, na indústria turística e, de forma indireta, em todo setor produtivo. Um dos fenômenos físicos decorrentes da variabilidade climática é a variabilidade da precipitação pluvial, um importante fator no controle do ciclo hidrológico e uma das variáveis climáticas que maior influência exercem na qualidade do meio ambiente. As quantidades relativas de precipitação pluvial (volume), seu regime sazonal ou diário (distribuição temporal) e as intensidades de chuvas individuais (volume/duração) são algumas das características que afetam direta ou indiretamente a população, a economia e o meio ambiente.

O clima regional é caracterizado pela interação dos sistemas meteorológicos com os elementos da paisagem geográfica, como o relevo, a latitude, a maritimidade e a continentalidade. A pluviosidade é condicionada principalmente pela dinâmica atmosférica em relação ao relevo que, através de sua compartimentação, promove a distribuição espacial da precipitação.

Esse estudo descreve e caracteriza o comportamento sazonal e mensal da precipitação pluvial através da análise do clima numa escala temporal considerando interações da dinâmica atmosférica regional com distribuição espacial da precipitação pluvial no Rio Grande do Sul. Esta descrição e caracterização foram feitas através de uma análise de estatística básica dos valores máximos da precipitação pluvial.

Através desta análise foi possível identificar estações meteorológicas cujos padrões do comportamento da precipitação pluvial são semelhantes e apontar possíveis fatores responsáveis por essas semelhanças entre estações diferentes, identificando os sistemas atmosféricos que atuam no Estado do Rio Grande do Sul.

\section{Climatologia do Estado do Rio Grande do Sul}

O Rio Grande do Sul situa-se na faixa subtropical, apresentando um clima de transição entre tropical e temperado. O Estado faz parte da Região Sul 
do Brasil, onde destaca-se a ocorrência de estação térmica fria, devido a atuação de massas de ar polar.

O clima do Rio Grande do Sul é do tipo mesotérmico, não possuindo uma estação chuvosa ou seca bem definida (NIMER, 1989). Portanto, alguns meses são mais chuvosos do que outros existindo variações regionais neste padrão.

Os totais médios anuais da precipitação pluvial distribuem-se, de modo geral, desde os $1200 \mathrm{~mm}$, na faixa litorânea, até os $1900 \mathrm{~mm}$, no setor norte do Estado. Em locais na borda da escarpa, como em São Francisco de Paula, chegam a mais de $2000 \mathrm{~mm}$ (NIMER, 1989).

Quanto à média anual de temperatura verifica-se que, em função da latitude e das superfícies de relevo, esta fica abaixo de $20^{\circ} \mathrm{C}$ na maior parte do Rio Grande do Sul, chegando a menos de $14{ }^{\circ} \mathrm{C}$ nas maiores altitudes. As médias das temperaturas mínimas do mês de julho são inferiores a $10^{\circ} \mathrm{C}$, com exceção do nordeste do Estado aonde chegam a $13^{\circ} \mathrm{C}$. No verão as médias das temperaturas máximas de janeiro apresentam-se bastante elevadas, sendo que no centro e oeste do Estado ultrapassam os $32^{\circ} \mathrm{C}$. (NIMER, 1989).

Segundo Nimer (1990), os principais centros de ação para a circulação do Rio Grande do Sul são os anticiclones permanentes e semifixos oceânicos. São eles: alta do Atlântico e a alta do Pacífico (Figura I).

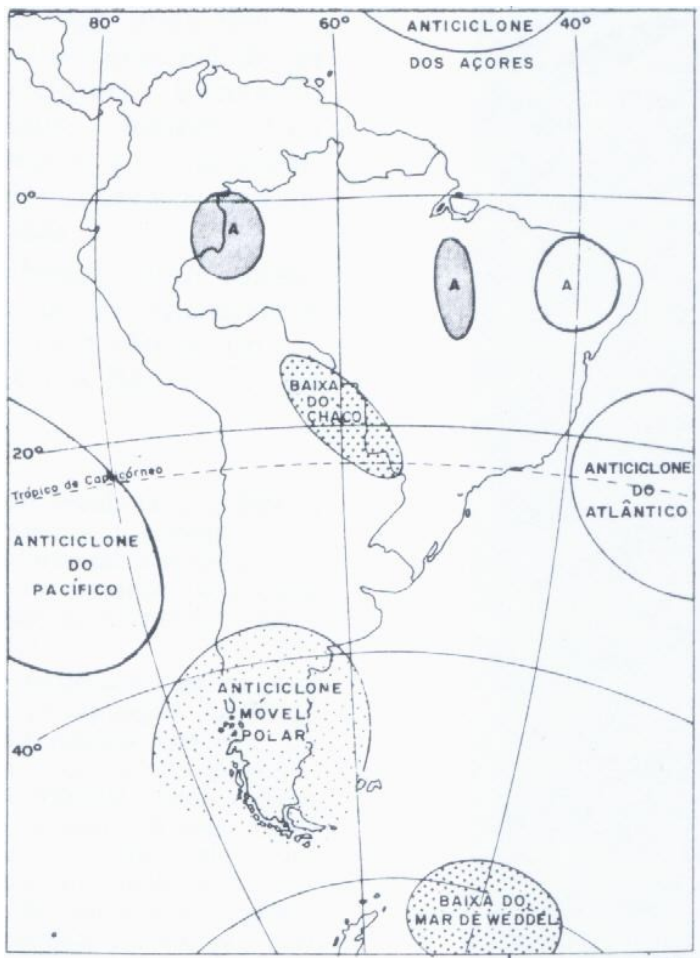

Figura 1. Os centros de ação.

Fonte: Hoffmann et al. (1997)

O anticiclone do Atlântico atua de modo a avançar sobre o continente, denominado de Anticiclone Semifixo do Atlântico Sul (ASAS), fonte principal da massa de ar Tropical Marítima. O ASAS atua sobre o litoral, transportando umidade e ocasionando formação de nuvens, principalmente no período noturno. Já o anticiclone do Pacífico é barrado pela Cordilheira dos Andes e muitas vezes é impedido de avançar para o interior do continente (NIMER, 1990).

De acordo com Monteiro e Furtado (1995) e Monteiro (2001), outro sistema tem tanta importância na circulação atmosférica do Rio Grande do Sul quanto o anticiclone do Atlântico. Trata-se da alta polar conhecida como anticiclone migratório Polar, oriundo das latitudes subpolares. O anticiclone polar deslocase sobre o Pacífico e cruza os Andes em diversas latitudes, de acordo com a estação do ano. A trajetória efetuada por esta alta pressão sobre o continente sul-americano, acaba determinando diversos tipos de tempo sobre a Região Sul do Brasil. 
Além dos anticiclones mencionados, outros sistemas atmosféricos participam da circulação do Rio Grande do Sul. São eles: as altas tropicais que invadem o Estado na primavera e no outono, originadas nas latitudes baixas do Brasil. (NIMER, 1990).

O centro negativo baixa pressão localizado no interior do continente sul-americano é denominado de baixa do Chaco. Este sistema também é importante na circulação do Rio Grande do Sul. Trata-se de uma baixa de origem termodinâmica e móvel, com posição média sobre a região do Chaco, limites BrasilBolívia. Durante o inverno, ela se encontra mais freqüentemente sobre o PeruAcre-Rondônia e, durante o verão, sobre a região do Chaco argentino. (NIMER, 1990).

A dinâmica das massas de ar tem ação decisiva na distribuição térmica e pluviométrica da região Sul do Brasil. O Rio Grande do Sul sofre a ação de massas de ar quente e fria (Tropicais e Polares). São elas: (i) a Massa Tropical Atlântica, quente e úmida, dispersora de ventos quentes, formada no Oceano Atlântico em área tropical; (ii) a Massa Polar Atlântica, muito fria, formada no sul da Argentina, sobre o oceano e (iii) a Massa Tropical Continental, quente e seca, formada sobre o Chaco. Esta última possui atuação mais restrita, é um centro de baixa pressão.

Por estar situado no extremo sul do País, o Rio Grande do Sul é influenciado com maior intensidade pela massa de ar polar. No inverno, a Massa Polar Atlântica avança no Estado de quadrante sul para nordeste (Figura II), possuindo três direções principais: (i) a Ocidental, avançando pela depressão do Chaco até a Amazônia ocidental; (ii) a Central, com maior atuação no Estado, que provoca quedas de temperatura e precipitação pluviométrica, seguido de ventos fortes de sul, sudoeste e oeste, caracteristicamente secos e frios e; (iii) a Oriental, que desloca-se sobre o oceano, próxima ao litoral brasileiro.

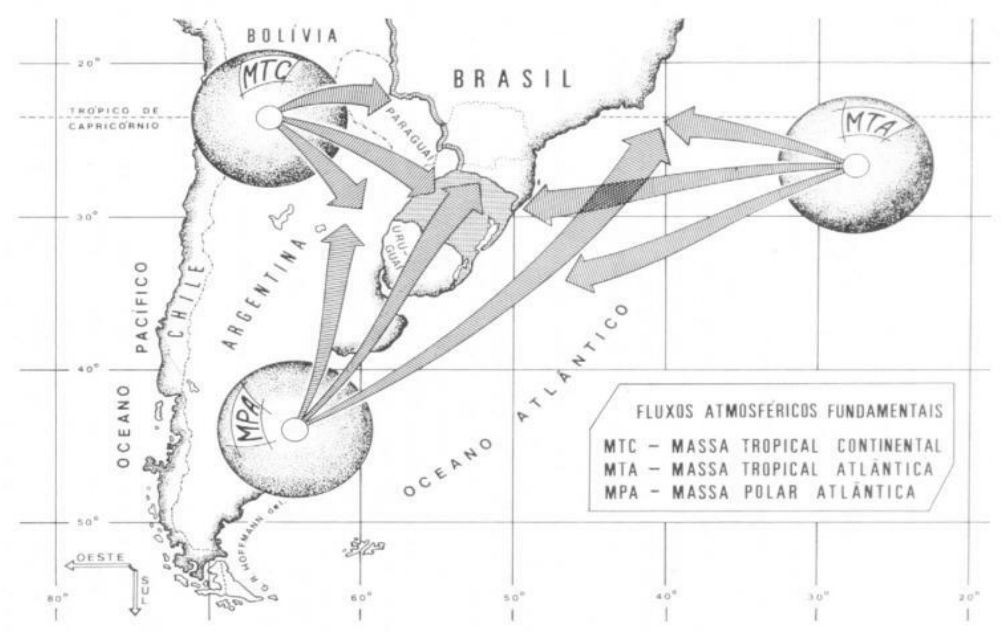

Figura 2. As massas de ar que atuam no Estado do Rio Grande do Sul.

Fonte: Nimer, 1990. 
A Massa Polar Atlântica ao avançar encontra-se com a Massa Tropical Atlântica, formando sistemas frontais responsáveis pelas chuvas de inverno no Estado. No verão as massas de ar que tem maior atuação são a Tropical Atlântica e a Tropical Continental. A ação da Massa de Ar Polar, nesta época, se reduz. A restrita penetração deste anticiclone no verão provoca chuvas intermitentes e chuvisco. A intensidade das chuvas nesta época depende da quantidade de umidade acumulada, associada à Zona de Convergência do Atlântico Sul (ZCAS), transportada para a região.

A Massa Tropical Atlântica situada nas proximidades do Trópico, sobre o oceano, durante o verão desloca-se mais para o sul, atuando com maior intensidade no Estado. Pode penetrar sem dificuldades para o interior, pela planície costeira e sem barreiras, acrescentando desta forma umidade à atmosfera.

\section{Sistemas de tempo que atuam no Rio Grande do Sul}

No Rio Grande do Sul, a localização latitudinal e as características geográficas favorecem a atuação sucessiva de sistemas de tempo característicos das latitudes médias, principalmente das massas de ar Tropical Atlântica e Polar Marítima. As características do relevo da América do Sul favorecem a atuação dos sistemas de circulação tropicais, principalmente durante o verão. (FONZAR, 1994).

O Estado do Rio Grande do Sul é afetado por diversos sistemas de tempo que são essenciais na determinação da precipitação. Entre os mais importantes, podemos citar a passagem de sistemas frontais sobre a região, que são responsáveis por grande parte da precipitação pluviométrica durante o ano. Estudos climatológicos mostram que em média 5 a 7 frentes frias passam pela região a cada mês (OLIVEIRA, 1986).

Monteiro e Furtado (1995) estudaram o clima do trecho FlorianópolisPorto Alegre, constatando que a precipitação é maior em Porto Alegre no trimestre de junho, julho e agosto. Tal variabilidade se deve às frentes estacionárias e ao fato do Rio Grande do Sul fazer parte de uma região denominada de frontogenética.

No trabalho realizado por Brandão e Lucena (2002) sobre tendência do clima no Centro - Sul das normais climatológicas entre os períodos 19311960 e 1961-1990, foi identificado que houve aumento na média em geral da pluviosidade anual em todas as regiões do Brasil. O aumento ocorreu em maior número de estações do Rio Grande do Sul em relação a outros estados, em mais de $70 \%$ das estações meteorológicas. Os acréscimos variaram, em média, até 200 mm, exceto em Caxias do Sul (263,8 mm) e São Luiz Gonzaga (305,5 mm). Segundo estes autores, o aumento das chuvas no Rio Grande do Sul pode estar atrelado aos avanços dos sistemas frontais, favorecido pelo El Niño Oscilação Sul (ENOS) que durante seu período de atuação intensifica o período de chuvas no sul.

Estudos realizados por Severo (1994), Severo et al. (1994) e Inazawa (1997), indicam que há uma interação entre as frentes frias em baixos níveis e o jato subtropical no Rio Grande do Sul, processos que podem ser respon- 
sáveis por intensa precipitação nesta região.

Outros sistemas que contribuem para o aumento da precipitação são os vórtices ciclônicos de altos níveis (VCAN) e cavados invertidos, que cruzam os Andes, oriundos do Pacífico e se intensificam sobre o sul e sudeste do Brasil (CAVALCANTI, 1985).

A ocorrência de ciclogêneses sobre o sul do Brasil também é um fator preponderante na determinação da precipitação desta região. Estudos estatísticos (GAN e RAO, 1991) mostram que a maior freqüência de ciclogêneses ocorre sobre o Uruguai durante o inverno no Hemisfério Sul. Em média, ocorrem cerca de 60 ciclogêneses sobre a Região Sul a cada ano.

Em uma escala menor, os Complexos Convectivos de Meso Escala (CCM's) também são responsáveis por precipitação intensa (GUEDES, 1985). Comuns na primavera, estes sistemas formam-se no período noturno no qual apresenta um máximo de convecção, geralmente sobre o sul do Paraguai e alcançam o sul do Brasil com intensa precipitação, em um curto espaço de tempo. Os sistemas convectivos são importantes na distribuição da precipitação no noroeste e norte do Estado.

Estudos realizados no sul do Brasil e São Paulo têm mostrado que o verão está dominado por sistemas convectivos oriundos do deslocamento da Zona de Convergência Intertropical (ZCIT), mais para o sul da linha do Equador, intensificando a Zona de Convergência do Atlântico Sul (ZCAS) e originando chuvas intensas no sul do Brasil, além de Minas Gerais e Rio de Janeiro. (NERY, 1996).

Sistema de tempo de grande escala que afeta a região é o fenômeno El Niño Oscilação Sul (ENOS). A evidência científica e a própria realidade têm demonstrado que o ENOS exerce um papel relevante nas anomalias climáticas de precipitação pluviométrica no Rio Grande do Sul. As anomalias climáticas mais conhecidas e de maior impacto são as relacionadas com o regime de precipitação pluviométrica, embora o regime térmico também possa ser modificado.

Particularmente no sul do Brasil, em-anos de El Niño, as chances de chuvas acima do normal são maiores, enquanto desvios negativos ocorrem em anos de La Niña. Apesar da influência dar-se durante todo o período de atuação desses eventos, há duas épocas do ano que são mais afetadas pelas fases do ENOS. São elas a primavera e começo de verão (outubro, novembro e dezembro), no ano inicial do evento; e final de outono e começo de inverno (abril, maio e junho), no ano seguinte ao início do evento. (CUNHA, 2003). Assim, nessas épocas, as chances de chuvas acima do normal são maiores, em ano de El Niño, e chuvas abaixo do normal, em anos de La Niña, influenciando o ritmo climático do Rio Grande do Sul, atuando sob o ritmo de deslocamento das frentes.

\section{Material e Métodos}

\section{Aquisição de dados}

Para a realização deste estudo foram utilizados dados mensais de precipitação pluvial do período entre 1967 a 1998, das seguintes estações mete- 
orológicas: Alegrete, Bagé, Bom Jesus, Caxias do Sul, Cruz Alta, Encruzilhada do Sul, Pelotas, Porto Alegre, Santa Maria, Santa Vitória do Palmar, Santana do Livramento, São Luiz Gonzaga, Torres e Uruguaiana distribuídas espacialmente no Estado do Rio Grande do Sul (Figura III).

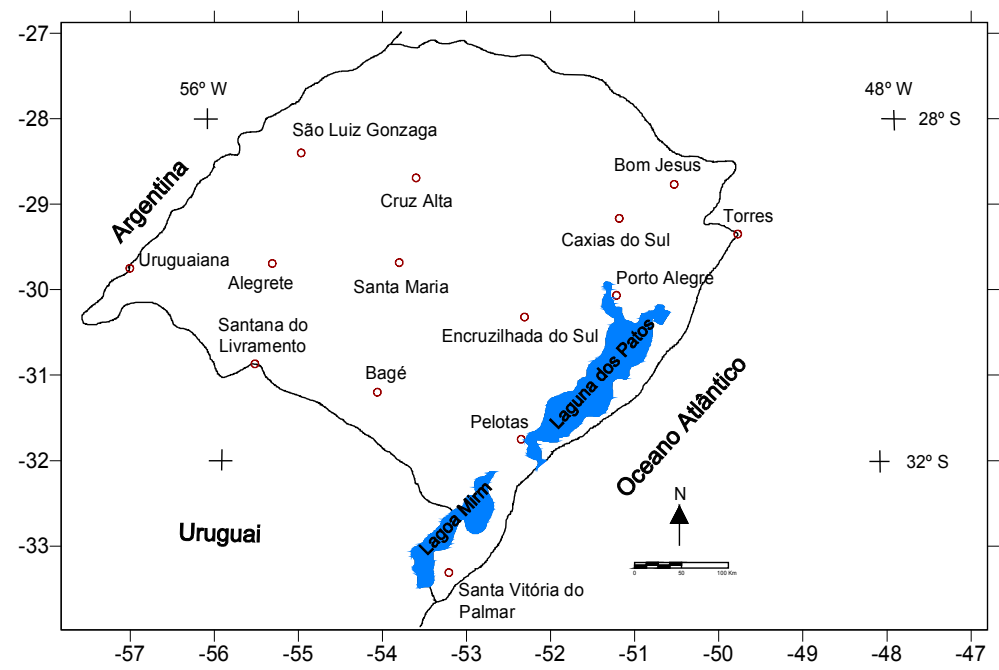

Figura 3. Distribuição espacial das estações meteorológicas.

A tabela I mostra as estações meteorológicas com suas respectivas latitudes, longitudes e altitudes. Os dados usados foram fornecidos pelo $8^{\circ}$ Distrito de Meteorologia - Porto Alegre (Instituto Nacional de Meteorologia INMET).

Tabela 1. Estações meteorológicas do Estado do Rio Grande do Sul e coordenadas geográficas

\begin{tabular}{lccc}
\hline \multicolumn{1}{c}{ Estação } & Latitude & Longitude & Altitude(m) \\
\hline Alegrete & $29^{\circ} 41^{\prime}$ & $55^{\circ} 31^{\prime}$ & 124 \\
Bagé & $31^{\circ} 21^{\prime}$ & $54^{\circ} 06^{\prime}$ & 215 \\
Bom Jesus & $28^{\circ} 40^{\prime}$ & $50^{\circ} 26^{\prime}$ & 1047 \\
Caxias do Sul & $29^{\circ} 10^{\prime}$ & $51^{\circ} 12^{\prime}$ & 785 \\
Cruz Alta & $28^{\circ} 38^{\prime}$ & $53^{\circ} 36^{\prime}$ & 472 \\
Encruzilhada do Sul & $30^{\circ} 32^{\prime}$ & $52^{\circ} 31^{\prime}$ & 427 \\
Pelotas & $31^{\circ} 52^{\prime}$ & $52^{\circ} 21^{\prime}$ & 13 \\
Porto Alegre & $30^{\circ} 1^{\prime}$ & $51^{\circ} 13^{\prime}$ & 46 \\
Santa Maria & $29^{\circ} 42^{\prime}$ & $53^{\circ} 42^{\prime}$ & 95 \\
Santa Vitória do Palmar & $33^{\circ} 31^{\prime}$ & $53^{\circ} 21^{\prime}$ & 6 \\
Santana do Livramento & $30^{\circ} 53^{\prime}$ & $55^{\circ} 32^{\prime}$ & 210 \\
São Luiz Gonzaga & $28^{\circ} 23^{\prime}$ & $54^{\circ} 58^{\prime}$ & 254 \\
Torres & $29^{\circ} 20^{\prime}$ & $49^{\circ} 43^{\prime}$ & 43 \\
Uruguaiana & $29^{\circ} 45^{\prime}$ & $57^{\circ} 05^{\prime}$ & 74 \\
\hline
\end{tabular}




\section{Processamento dos dados}

O comportamento espaço - temporal da precipitação pluvial foi analisado através da variabilidade sazonal e mensal. Para esta análise e interpretação dos dados, efetuou-se a plotagem de gráficos de distribuição dos totais de precipitação pluvial. Foram calculados e analisados os totais médios de pluviosidade nas escalas de tempo sazonal e mensal para cada estação meteorológica, com a utilização do programa EXCEL.

Posteriormente, foram identificados os sistemas dinâmicos que atuam em cada estação do ano (inverno, primavera, verão e outono) no Rio Grande do Sul. Classificou-se como estação de inverno, os meses de junho, julho e agosto; primavera os meses de setembro, outubro e novembro; verão os meses de dezembro, janeiro e fevereiro; e como outono, os meses de março, abril e maio.

Para identificar estações meteorológicas cujos padrões do comportamento da precipitação pluvial são semelhantes, comparou-se os máximos de pluviosidade de cada estação meteorológica por estação do ano e por mês, visando a regionalização sazonal da precipitação pluviométrica.

\section{Resultados e discussão}

\section{Variabilidade sazonal da precipitação pluviométrica máxima}

\subsection{Inverno}

De acordo com os resultados obtidos, Sta. Vitória do Palmar, Pelotas, Bagé, Encruzilhada do Sul, Santa Maria, Porto Alegre e Caxias do Sul (Figura IV), tiveram seus máximos de precipitação pluvial nos meses de inverno. Estas áreas apresentaram precipitação pluviométrica total inferior a $450 \mathrm{~mm}$ (Figura V).

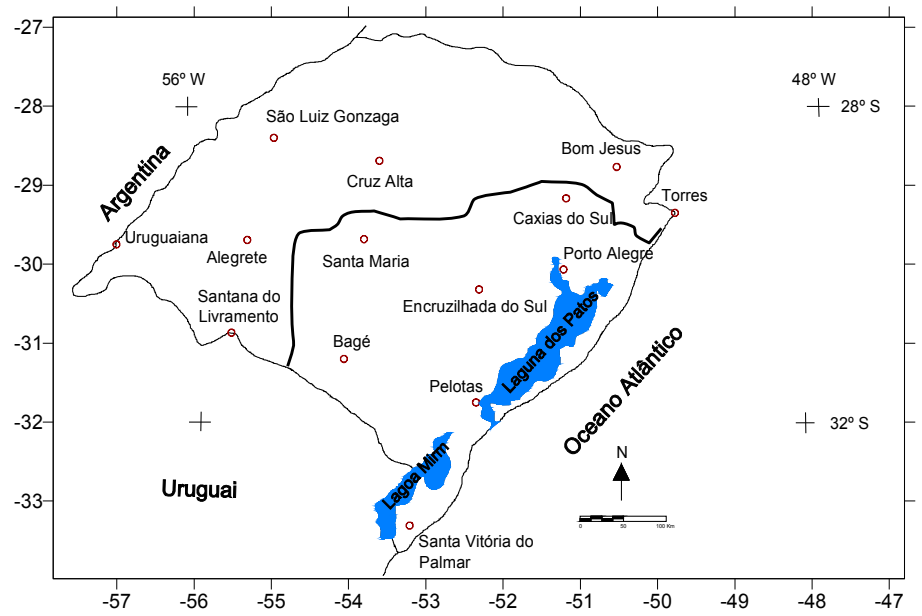

Figura 4. Regionalização da precipitação pluvial na estação de inverno (1968-1998). 

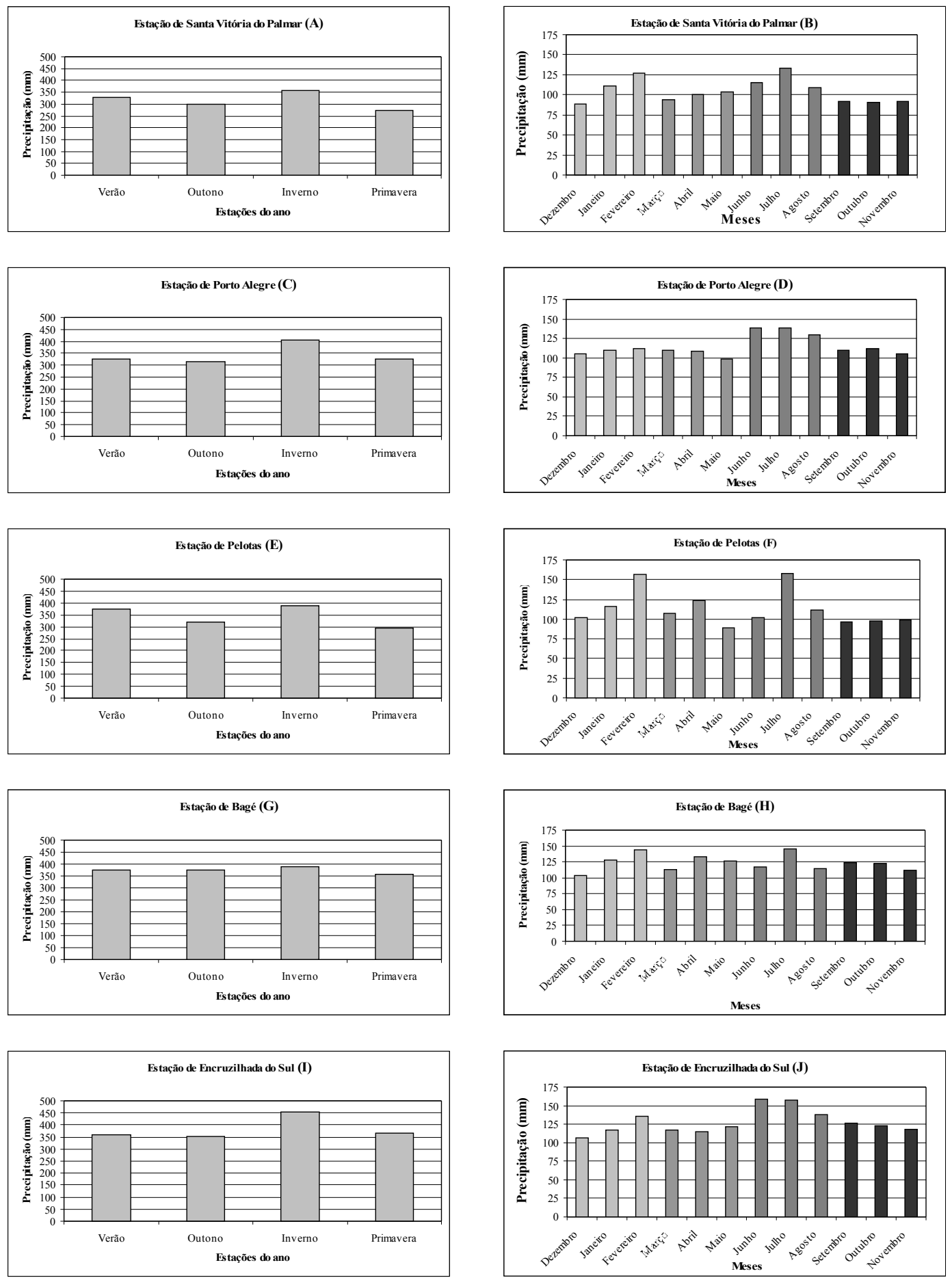

Figura 5. Gráficos $A, B, C, D, E, F, G, H, I$ e $J$ de precipitação pluvial total sazonal e mensal (1967-1998). 
Britto, FP et al. Regionalização sazonal e mensal da precipitação ...
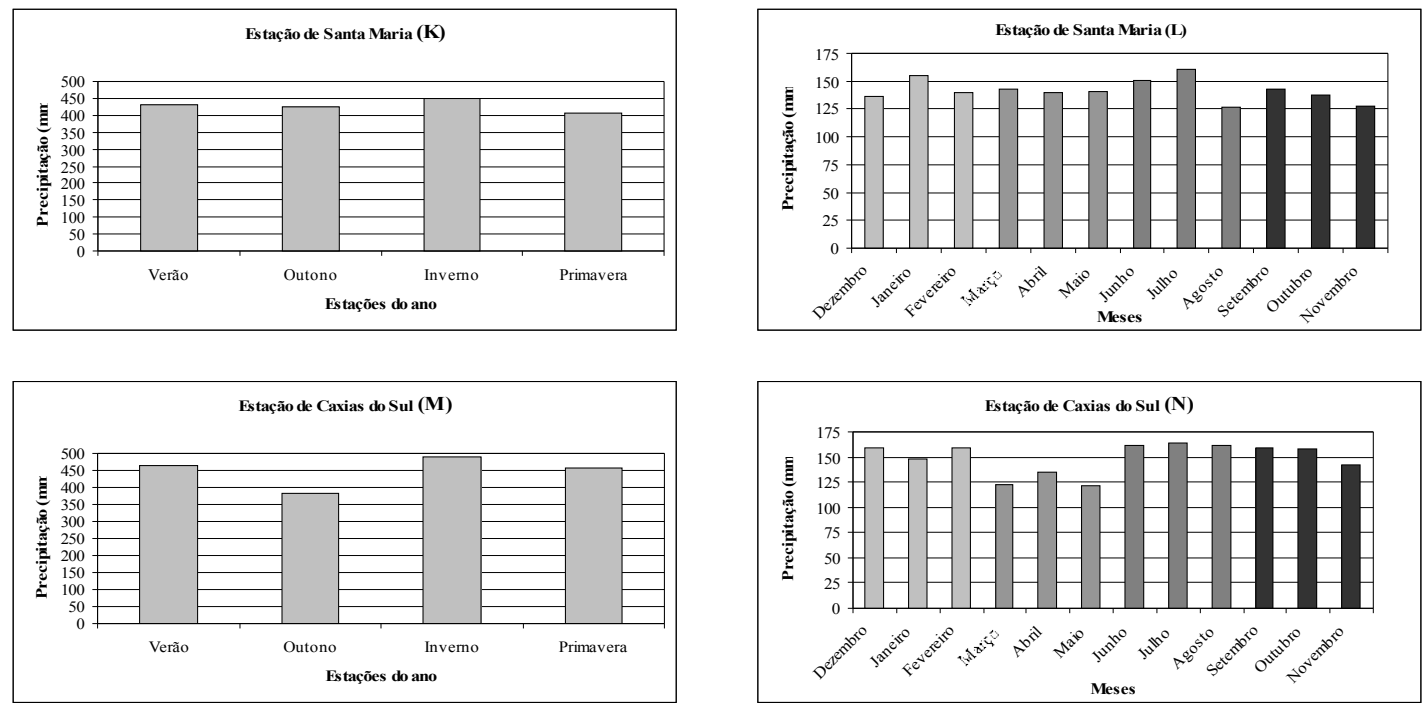

Figura 5 (cont...). Gráficos $K, L, M$ e $N$ de precipitação pluvial total sazonal e mensal (1967-1998).

A localidade de Caxias do Sul é uma exceção, pois apresentou precipitação pluviométrica total de $488 \mathrm{~mm}$. Caxias do Sul está localizada na região serrana no Planalto das Araucárias, numa altitude de $785 \mathrm{~m}$. Neste caso, ocorre o efeito barlavento, pois o sistema frontal ao encontrar a escarpa é forçado a subir, a temperatura declina por expansão adiabática, forçando a saturação, daí ocorrendo maior precipitação pluviométrica nesta área no inverno.

No inverno, o Rio Grande do Sul situado no extremo sul do país, é influenciado com maior intensidade pela massa de ar Polar proveniente do continente Antártico. Esta massa de ar é a responsável pelas ondas de frio, podendo causar geada e neve, fenômenos típicos da estação. Durante o inverno, o deslocamento das massas polares é mais continental.

O que caracteriza o Rio Grande do Sul quanto à circulação atmosférica é que é uma região frontogenética, ou seja, os sistemas frontais podem se formar ou podem se intensificar. De acordo com Nimer (1989), esta circunstância torna o Estado sujeito às sucessivas entradas frontais que alcançam a extraordinária regularidade de uma invasão por semana. Durante o inverno, os avanços dos sistemas frontais são mais vigorosos, podendo até alcançar latitudes bem mais baixas. Os sistemas frontais ocorrem com mais freqüência e com maior velocidade de deslocamento, causando nebulosidade principalmente no litoral. Isto acontece devido à impossibilidade do ar quente e úmido ser renovado durante o curto intervalo de tempo entre os sistemas frontais, onde a nova frente irá encontrar o ar relativamente frio deixado pela precedente (LEMOS e CALBETE, 1998).

Os sistemas frontais são os principais sistemas produtores de tempo responsáveis por precipitação pluviométrica no inverno no Rio Grande do Sul. Nesta estação do ano, a frente fria em superfície se apresenta com uma orientação mais noroeste/sudeste. A maior freqüência de passagens dos sistemas frontais acontece no período de inverno, por esta razão que as estações meteoroló- 
gicas situadas próximas do litoral e no centro-sul, apresentam máxima taxa de precipitação pluvial neste período.

\subsection{Primavera}

Setembro e outubro caracterizam-se como os meses mais chuvosos para as localidades de São Luiz Gonzaga e Cruz Alta (Figura VI), apresentando precipitação pluviométrica total de $517 \mathrm{~mm}$ e $491 \mathrm{~mm}$, respectivamente (Figura VII).

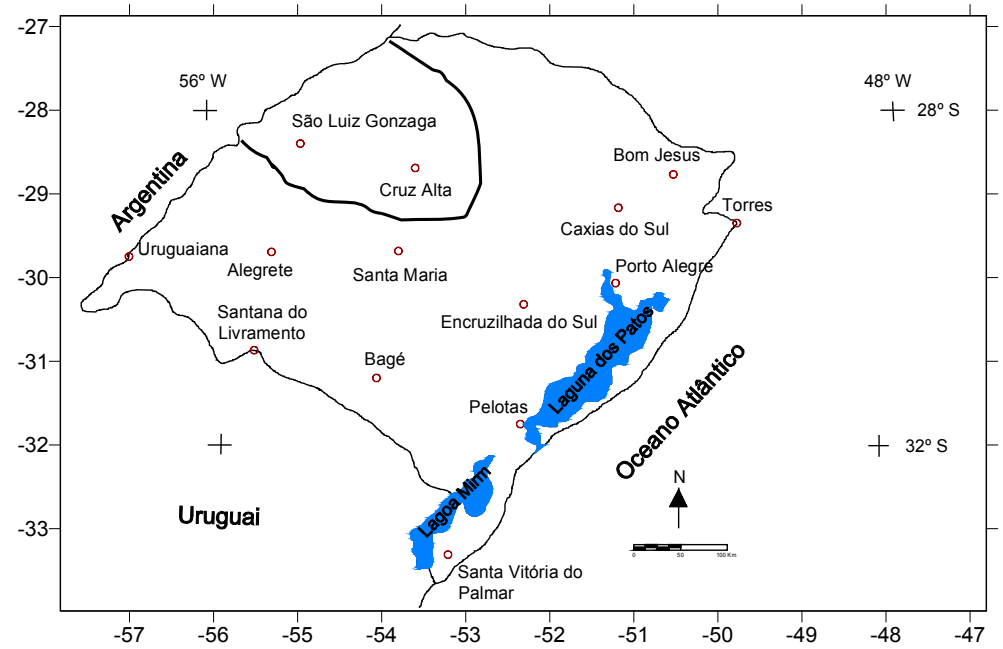

Figura 6. Regionalização da precipitação pluvial na estação de primavera (1968-1998).

Na primavera não se observa uma mudança rápida do mecanismo de circulação existente no inverno, porém ocorre uma diminuição na freqüência e intensidade das ocorrências das massas polares. Contudo, ainda pode ocorrer incursão de massas de ar frio nos meses de setembro e outubro, causando declínio da temperatura, ocorrências de geadas. Em situações extremas, pode ser observada precipitação de neve nas áreas serranas.

Na primavera, o Rio Grande do Sul é regularmente invadido por ventos de noroeste e sudoeste, ocorrendo freqüentes formações de Complexos Convectivos de Mesoescala (CCM's). Os CCM's são sistemas que se formam no período noturno sobre o norte da Argentina e sul do Paraguai e deslocam-se rapidamente atingindo o noroeste do Estado com intensa precipitação pluvial. Conforme Velasco e Fritsch (1987), os CCM's são responsáveis por situações de tempo severo, com presença de fortes ventos, inundações e por vezes granizos. Estes sistemas são responsáveis por significativa parcela da precipitação pluviométrica na primavera, que ocorre no noroeste do Rio Grande do Sul. Isto acarreta em índices pluviométricos mais elevados neste período em São Luiz Gonzaga e Cruz Alta. Provavelmente a distribuição espacial das chuvas nestas áreas ocorre em função da dinâmica atmosférica, possivelmente por estarem situadas no planalto o ativamento da turbulência do ar sobre estas áreas também corrobora para maior produção de chuvas. 

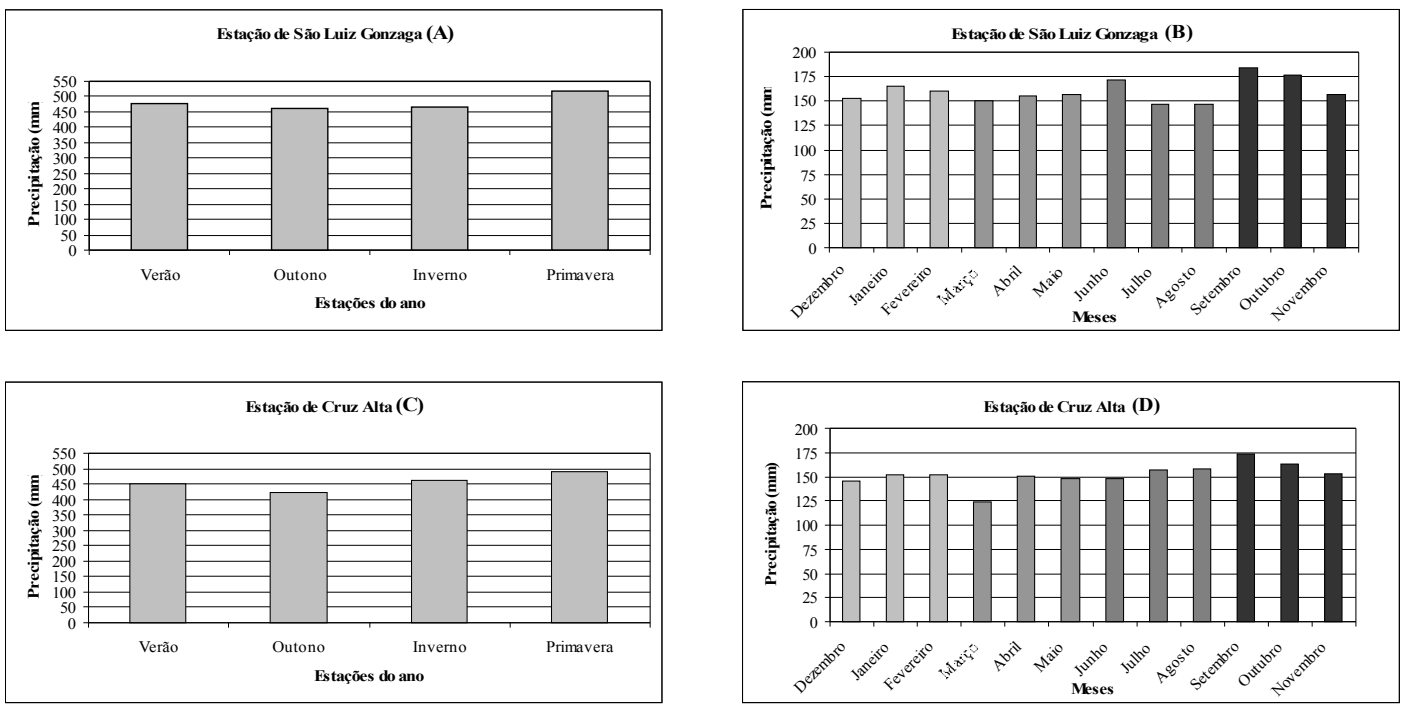

Figura 7. Gráficos $A, B, C$ e $D$ de precipitação pluvial total sazonal e mensal (19671998).

\subsection{Verão}

O município de Bom Jesus (localizado numa altitude de $1047 \mathrm{~m}$ ) e Torres (Figura VIII), tiveram seus máximos de precipitação pluvial nos meses de verão. Estas áreas apresentaram totais médios de $486 \mathrm{~mm}$ e $415 \mathrm{~mm}$, respectivamente (Figura IX).

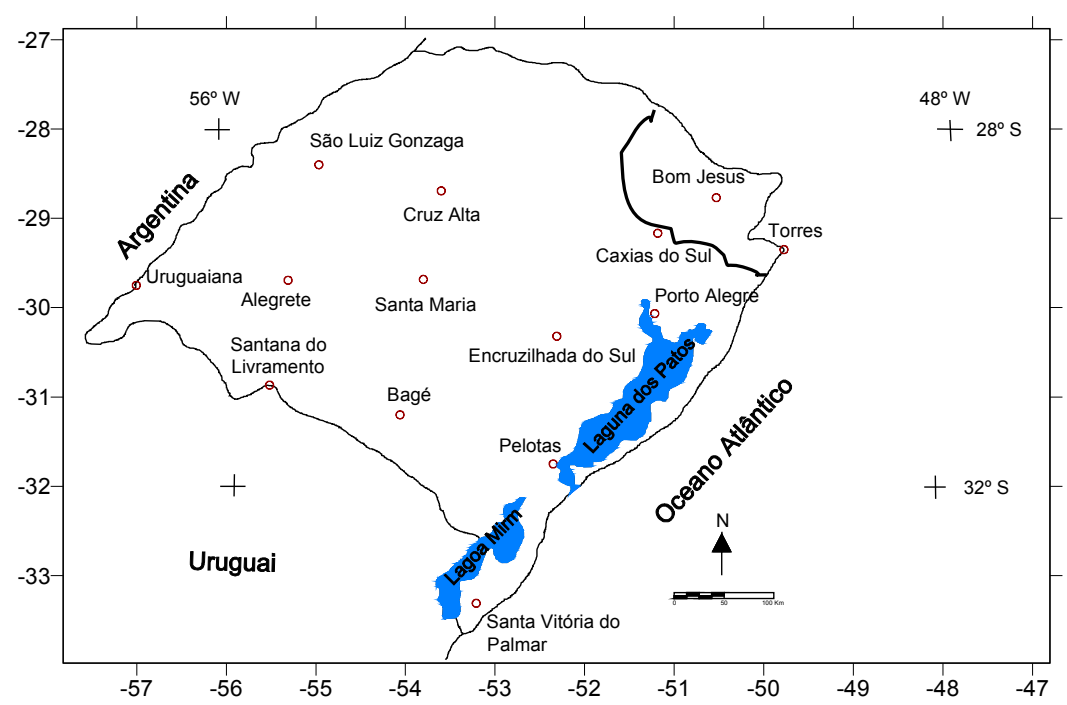

Figura 8. Regionalização da precipitação pluvial na estação de verão (1968-1998). 

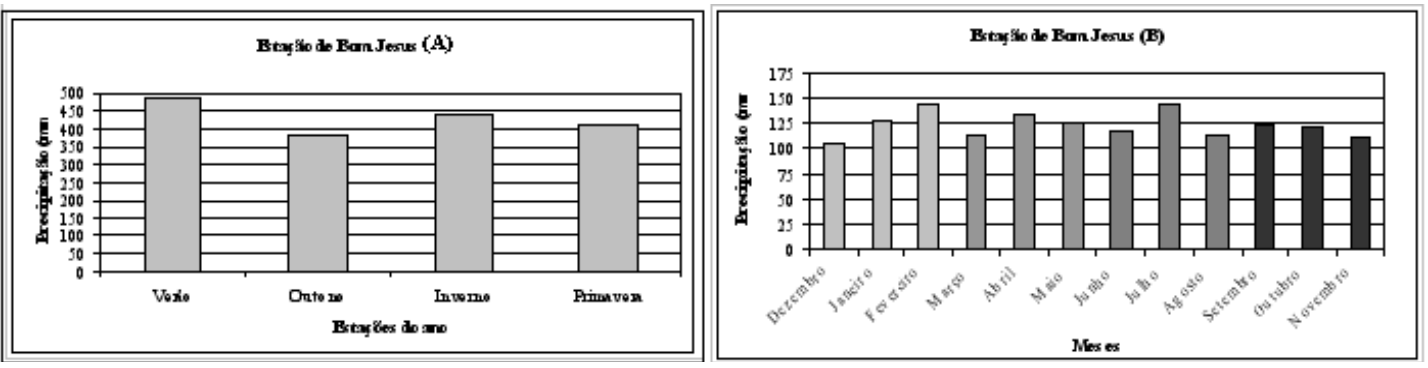

Figura 9. Gráficos A e B de precipitação pluvial total sazonal e mensal (19671998).

No verão os centros de ação já apresentam novas disposições e o mecanismo da circulação regional segue uma dinâmica diferente. Nesta estação do ano a massa de ar Tropical Atlântica de característica quente e úmida tem maior atuação. Durante o verão esta massa desloca-se mais para o sul, atuando com maior intensidade no norte Estado. A ação da massa de ar Polar, nesta época, se reduz e as ondas de frio são fracas.
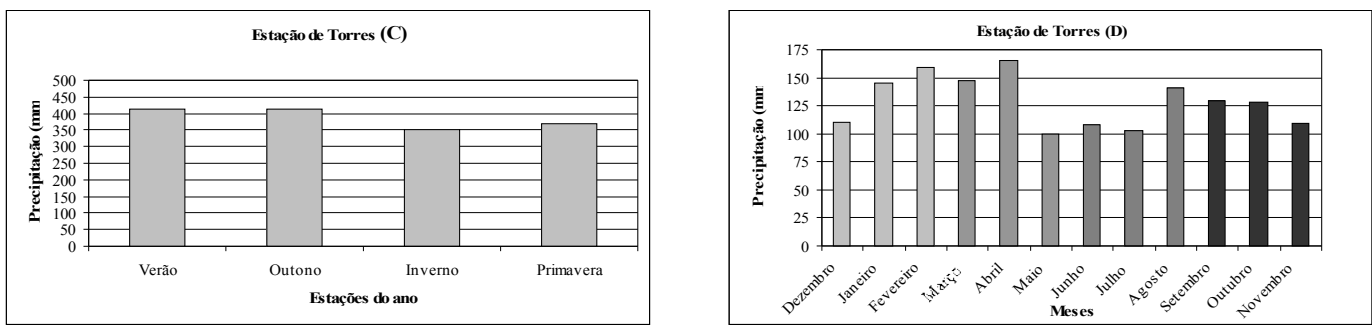

Figura 9 (cont...). Gráficos C e D de precipitação pluvial total sazonal e mensal (1967-1998).

Devido à alta intensidade do calor no verão, associada aos altos índices de umidade, as chuvas geralmente são convectivas, formando nuvens do tipo cumulonimbus. Estas podem se desenvolver verticalmente em condições específicas de calor acentuado e quantidade de umidade que resultam em fortes pancadas de chuvas geralmente acompanhadas de trovões que podem durar uma ou poucas horas, principalmente no período da tarde devido ao calor. As chuvas convectivas ocorrem em conseqüência do diferente aquecimento basal da atmosfera em contato com uma superfície heterogênea podendo ser restritas à escala local ou proveniente da advecção de uma massa de ar (TAVARES, 1981).

A formação de chuvas no nordeste do Estado também pode estar associada à Zona de Convergência do Atlântico Sul (ZCAS). As ZCAS são áreas de instabilidade que orientam-se de noroeste para sudeste. Este sistema atmosférico forma uma banda de nebulosidade e chuvas, desde o sul do Amazonas, passando pela Região Central do Brasil, chegando até o norte do Estado do Rio Grande do Sul. 
A umidade que proporciona a ocorrência de chuvas no norte gaúcho é influenciada pela posição da ZCAS, citada por Monteiro e Furtado (1995) como assíntota de convergência. O centro-sul do Rio Grande do Sul, apresenta chuvas convecticas menos freqüentes devido a atuação da massa Tropical Continental

Em Bom Jesus e Torres ocorrem as chuvas convectivas associadas a ZCAS. Esta porção do Rio Grande do Sul recebe nesta época do ano atuação da massa Tropical, onde o aquecimento basal e a instabilidade da massa de ar acentuada pelo relevo da Serra Geral, acarretam no aumento da pluviosidade. A quantidade de precipitação pluviométrica nestas áreas está associada aos sistemas de tempo que atuam no verão, com mais influência dos regimes tropicais.

\subsection{Outono}

As estações meteorológicas localizadas em Uruguaiana, Alegrete e Santana do Livramento (Figura $X$ ) tiveram um aumento da pluviosidade no outono, com precipitação pluviométrica total de $464 \mathrm{~mm}, 470 \mathrm{~mm}$ e $410 \mathrm{~mm}$, respectivamente (Figura XI).

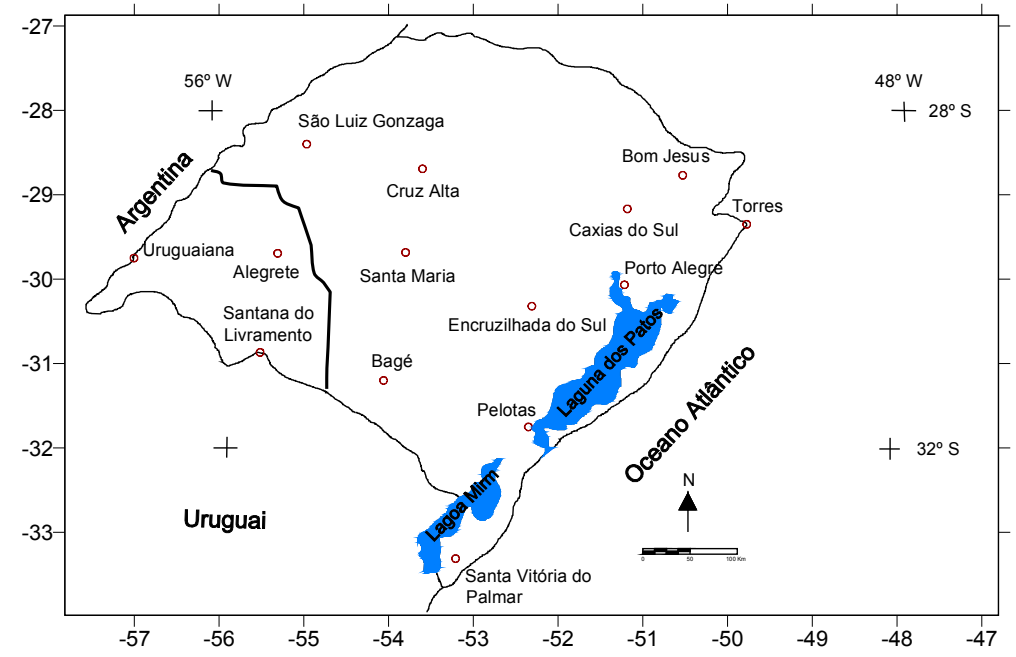

Figura 10. Regionalização da precipitação pluvial na estação de outono (1968-1998).

O outono é um período com características transicionais. Os tipos de tempo que atuam durante o início do outono, apresentam-se ora com características de verão, ora com características de inverno. No outono são observadas as primeiras entradas de massas polares, que provocam queda de temperatura, anunciando a chegada do inverno. Nesta estação as massas Tropicais Continentais, tornam-se mais ativas quando ocorrem os bloqueios atmosféricos, fazendo com que as frentes polares, fiquem estacionadas no Rio Uruguai e sul do Rio Grande do Sul.

De acordo com Rex (1950), bloqueio é uma situação em que a propagação para leste é bloqueada pelo desenvolvimento de um anticiclone quase estacionário de grande amplitude. Quando esta alta se estabelece, torna- 
se persistente e impede a propagação dos sistemas frontais. A região onde a alta de bloqueio atua é caracterizada por céu livre de nebulosidade e a temperatura se mantém acima da normal. Segundo Titarelli (1972), esta situação caracteriza os veranicos de maio, períodos relativamente quentes que afetam o sul do país.
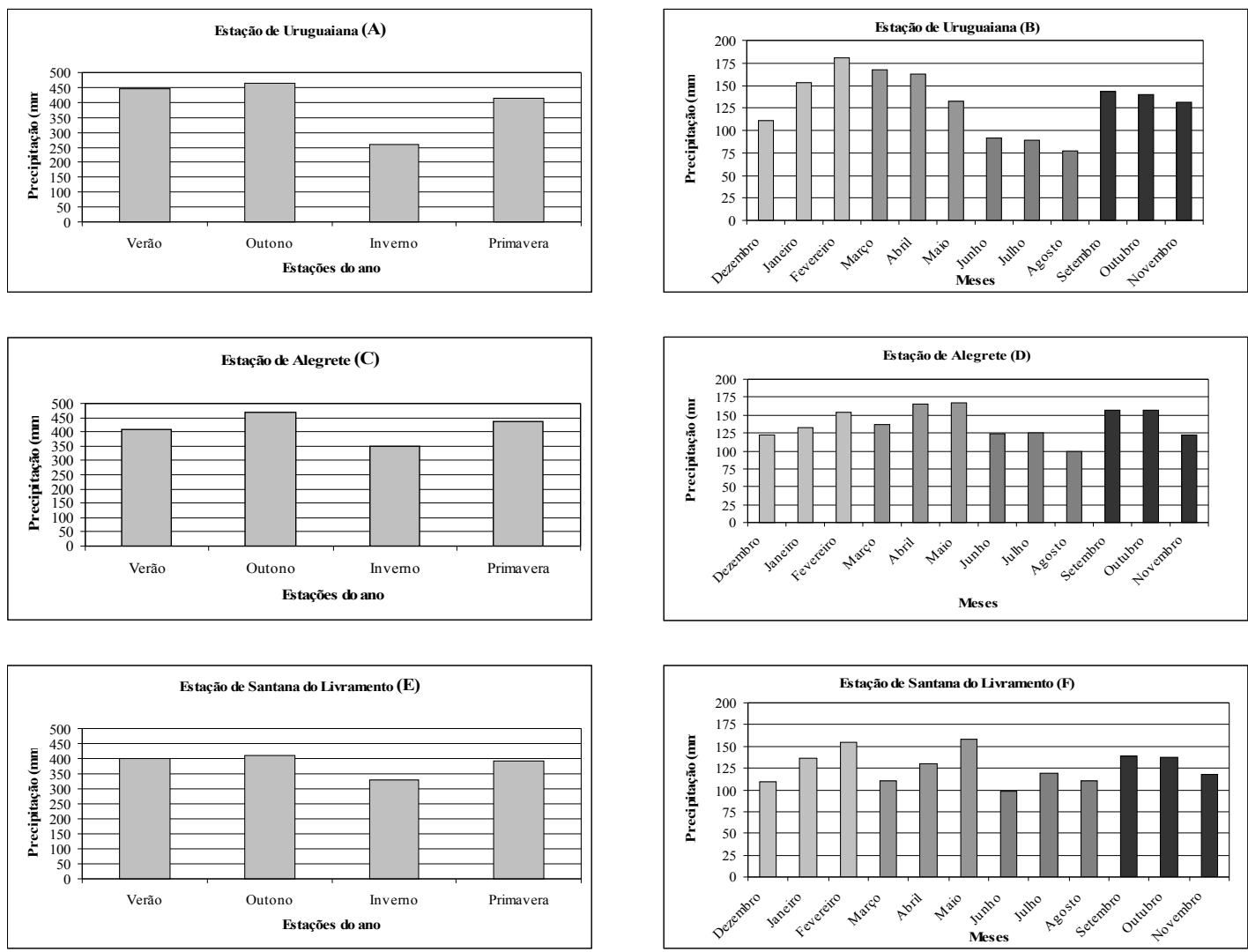

Figura 11. Gráfico $A, B, C, D$ e $F$ de precipitação pluvial total sazonal e mensal (1967-1998).

A influência de um bloqueio no Rio Grande do Sul depende da posição do anticiclone semi-fixo. Quando este estiver mais para oeste, vindo do Oceano Pacífico, ocorrem chuvas intensas no Estado. Estudo realizado por Casarin (1983), mostra que a freqüência máxima de bloqueios no Rio Grande do Sul ocorre no outono e o mínimo ocorre no inverno e na primavera.

O máximo de pluviosidade em Uruguaiana, Alegrete e Santana do Livramento, deve estar associado a deslocamentos mais continentais dos sistemas frontais nesta época do ano. Estas estações situadas mais ao sul são as primeiras a serem invadidas pelas frentes frias. Nestas áreas além dos sistemas frontais chegarem primeiro, ficam bloqueados pela atuação da massa Tropical ao norte, oscilando mais freqüentemente entre o rio da Prata (norte do Uruguai) e o sul do Rio Grande do Sul. Esta configuração atmosférica resulta na ocorrência de chuvas contínuas que chegam a durar, em algumas vezes, mais de uma semana, favorecendo volumes pluviométricos significativos. 


\section{Considerações finais}

Estudando a variabilidade mensal e sazonal, foram observados no Rio Grande do Sul quatro sub-regiões com valores de pluviosidade total semelhantes. Durante o inverno, chove mais na sub-região do litoral e no centro-sul, sendo responsável pela pluviosidade o sistema atmosférico frontal.

Durante a primavera, chove mais na sub-região noroeste do Rio Grande do Sul, onde dominam os Complexos Convectivos de Mesoescala (CCM's).

No verão chove mais na sub-região nordeste do Estado atingida por chuvas convectivas associadas às Zonas de Convergência do Atlântico Sul (ZCAS).

No outono chove mais na sub-região sudoeste do Estado e o sistema dinâmico mais influente é o bloqueio atmosférico.

Poucas informações sobre a influência do relevo nos valores totais de precipitação pluviométrica foram inferidas neste trabalho. Porém, sob uma análise preliminar, o relevo do Rio Grande do Sul, caracterizado por superfícies e formas simples, pareceram determinar grandes diferenciações na variabilidade sazonal da precipitação pluvial. A relação entre os valores totais de precipitação pluviométrica e altitude será estudada em Britto e Barletta (em preparação). Preliminarmente, a influência da altitude na precipitação ficou mais evidente nas estações meteorológicas de Caxias do Sul e Cruz Alta no inverno e na estação meteorológica de Bom Jesus no verão. Uma vez, que situadas ao norte, apresentam totais pluviais superiores àquelas situadas ao sul, com baixas altitudes. Nestas estações, a altitude é responsável pela intensificação das precipitações frontais e também convectivas, como no caso de Bom Jesus.

\section{Referências bibliográficas}

BRANDÃO, A.M. de P.M.; LUCENA, A.J. Tendência do clima no Centro-Sul das normais climatológicas. In: Simpósio Brasileiro de Climatologia Geográfica, Curitiba, 5, 2002. [CD ROM].

BRITTO, F.; BARLETTA, R. Influência da altitude na distribuição pluviométrica no Estado do Rio Grande do Sul. (Em preparação).

CASARIN, D. P. Um estudo obsevacional sobre os sistemas de bloqueio no Hemisfério Sul. Instituto de Pesquisas Espaciais, São José dos Campos, 2638 TDL/114, 1983.

CAVALCANTI, I.F. Casos de intensa precipitação nas Regiões Sul e Sudeste do Brasil no período de inverno de 1979 a 1983. Instituto de Pesquisas Espaciais, São José dos Campos, 3743, RPE/498, 1985.

CUNHA, G. R. La Niña e a agricultura no sul do Brasil. 2003. Acesso em: 08/06/2003. Disponível em: http://www.cnpt.embrapa.br/agromet.htm.

FONZAR, B.C. A circulação atmosférica na América do Sul. Os grandes sistemas planetários e subsistemas regionais que atingem o continente: localização e trajetórias. Caderno de Geociências. Instituto Brasileiro de Geografia e Estatística, Rio de Janeiro, v. 11, p. 11-33, 1994. 
GAN, M.A.; RAO, V.B. Surface cyclogenesis over South America. Mon. Weather Rev., 119, 1991.

GUEDES, R. L. Condições de grande escala associadas a sistemas convectivos de mesoescala sobre a Região Central da América do Sul. São Paulo, 1985. Dissertação de Mestrado - Instituto Astronômico e Geofísico, Universidade de São Paulo.

HOFFMANN, G. R.; AREND, L. M.; SILVEIRA, J. C. B.; BELLOMO, H. R.; NUNES, J. L. M. Rio Grande do Sul: Aspectos da Geografia. Porto Alegre: Martins Livreiro, 4a edição, 1997. 104p.

INAZAWA, E.E. Modelagem numérica da interação entre jatos subtropical e sistemas frontais em baixos níveis nas Regiões Sul e Sudeste do Brasil. São Paulo, 1997, 71p. Dissertação de Mestrado - Instituto Astronômico e Geofísico, Universidade de São Paulo.

LEMOS, C.F., CALBETE, N. O. Período de tempo que os sistemas frontais atuaram entre a cidade de Porto Alegre e Rio de Janeiro (período 1988-1993). In: Congresso Brasileiro de Meteorologia. Brasília, 10, 1998, Distrito Federal. Anais... Distrito Federal, 1998.

MONTEIRO, M.A.; FURTADO, S.M. O clima do trecho Florianópolis - Porto Alegre: uma abordagem dinâmica. GEOSUL, Florianópolis, n. 19/20, p. 117-133, 1995.

MONTEIRO, M.A. Caracterização climática do estado de Santa Catarina: uma abordagem dos principais sistemas atmosféricos que atuam durante 0 ano. GEOSUL, Florianópolis, v. 16, n. 31, p. 69-78, 2001.

NERY, J.T. Estudio climático de la precipitación del Brasil Meridional asociados com extremos extrarregionales. Buenos Aires- Argentina, 1996. Tese de Doutorado.

NIMER, E. Climatologia do Brasil. Departamento de Recursos Naturais e Estudos Ambientais, Instituto Brasileiro de Geografia e Estatística, Rio de Janeiro, $2^{a}$ edição, 1989. 422p.

NIMER, E. Clima. In: FURLANETTO, D.A. et. al. Geografia do Brasil: Região Sul. Rio de Janeiro: Instituto Brasileiro de Geografia e Estatística, V. 2, p. 151-187,1990. 420p.

OLIVEIRA, A.S. Interações entre sistemas frontais na América do Sul e a convecção da Amazônia. São José dos Campos, 1986, 134p. Dissertação de Mestrado - Instituto de Pesquisas Espaciais.

REX, D.F. Bloing action in the middle troposphere and it's effect upon regional climate. Tellus, Parte I, Parte II, v. 2, 1950.

SEVERO, D.L. Estudo de casos de chuvas intensas em Santa Catarina. São José dos Campos, 1994, 90p. Dissertação (Mestrado em Meteorologia) - Instituto Nacional de Pesquisas Espaciais.

SEVERO, D.L.; GAN, M.A.; FERREIRA, N.J. Estudo de um caso de chuvas intensas associado a enchentes na Região do Vale do Itajaí, em Santa Catarina. In: VIII Congresso Brasileiro de Meteorologia, 8, 1994, Belo Horizonte. Anais... Belo Horizonte,1994. P. 561-564, 1994.

TAVARES, A.C. A análise da distribuição das precipitações associadas às calhas induzidas no Estado de São Paulo. Publicação do Instituto de Geografia (IGOG) da Universidade de São Paulo. Série Climatologia, São Paulo, n. 12, 1981.

TITARELLI, A.H.V. A onda de frio de abril de 1971 e sua repercussão no Espaço Geográfico Brasileiro. Publicação do Instituto de Geografia (IGEOG) da Universidade de São Paulo. Série Climatologia, São Paulo, n. 04, 1972.

VELASCO, I.; FRITSCH, J.M. Mesoescale convective complexes in the Americas. Journal Geophysical Research,. 92, D8, p. 9591-9613, 1987. 
Britto, FP et al. Regionalização sazonal e mensal da precipitação ... 